\title{
AQUIFER CHARACTERISTICS AND GROUNDWATER POTENTIAL OF ARIGBAJO BASEMENT, OGUN STATE, NIGERIA
}

\author{
Sunday .J. Akinpelu \\ Department of Physical Sciences, Bells University of \\ Technology, Ota, Ogun State, Nigeria \\ Moriamo Adesegun \\ Department of Physics, University of Lagos Akoka \\ Lagos State Nigeria
}

\begin{abstract}
This research focuses on prospecting for groundwater, the depth at which it can be found and the quantity as well as its quality in the research area.
\end{abstract}

The 2-D resistivity method was adopted. Five traverse stations were mapped and a total of sixty-four (64) electrodes were used in each station, using the ABEM Terrameter SAS 4000 and electrode selector (ES464). RES-2D package was used for analysis and the results were presented in 2-D imaging.

The five stations show a resistivity range between $1 \Omega \mathrm{m}$ to $60,00 \Omega \mathrm{m}$. all the stations show resistivity averaging between 10 and $100 \Omega \mathrm{m}$ at the depth of 30,17, 26, 40 and 50 meters respectively. There resistivities shows the presence of groundwater, while stations 2,3 and 4 shows that the volume is reasonably high with average of $10 \mathrm{~m}$ thick. Stations 2 and 5 indicates that the aquifer is unconfined and at a shallow depth of $2 \mathrm{~m}$ and $15 \mathrm{~m}$ respectively. All the samples indicate the presence of silt, alluvia, oil sand, and sandy clay which are essential for groundwater aquifer at the aquifer depth of their respective stations.

Higher resistivities between $200 \Omega \mathrm{m}$ to about $1100 \Omega \mathrm{m}$ which is the resistivity range for limestone, dolomite and shale (Loke M. H. 1994) was also observed at deferent depth ranging from $32 \mathrm{~m}$ in station 1 to $22 \mathrm{~m}$ in station 2.

Resistivities of higher values above $1000 \Omega$ m which appear in all the sample is an evidence for gabbros, granite, quartzite etc. present at different depths and thicknesses.

\author{
Grace Aquah \\ University of Calabar, Cross River State, \\ Nigeria \\ Ibraheem A. Oladosu \\ Department of Basic Sciences, Adeleke University, \\ Ede, Osun State, Nigeria
}

Key words: aquifer, aquitard, geomorphic, outcropping.

\section{INTRODUCTION}

Groundwater has been a preferred source of drinking water because it is of higher quality, it is less susceptible to contamination and require little or no chemical treatment. Groundwater provides a reasonably constant supply that is not likely to dry up under natural conditions, as surface sources may do (Nwankwoala, 2011). The availability and accessibility to fresh and potable water is very important for human survival. Groundwater constitutes the only reliable water supply source for drinking and irrigation purposes (Uma K.O, 1989). It is exceptionally important as a source of relatively low-cost and high-quality domestic water supply in rural and urban centers of the developing countries such as Nigeria. Increase demand for water intake owing to the global worming couple with inadequate supply of pipeborne water in Arigbajo area of Ogun state underscores the need to rely on groundwater resource for use in domestic, industrial and agricultural requirement.

This research is therefore in line with the need of the people to uncover the groundwater potential and the dept to which a bore-hole can be sunk to pump a useable amount of water and also to determine the subsurface sratigraphy in the area.

The resistivity of a geological structure can vary significantly, depending on the porosity, water content and the concentration of salts in groundwater (Rhett H, 2001). This enables both a quantification of the water content and an estimation of the groundwater quality. 


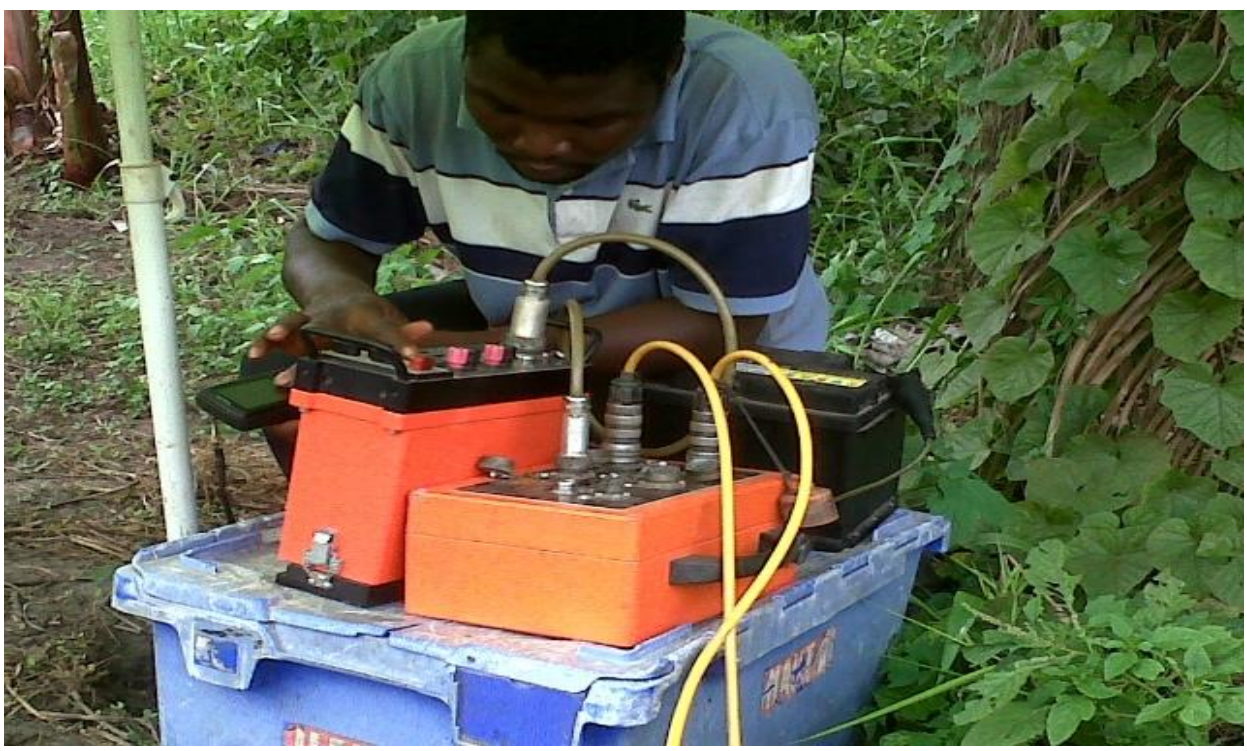

fig 1. Data collection on site at Arigbajo.

The resistivity of fresh groundwater varies usually from 7 to $100 \Omega \mathrm{m}$, depending on the degree of dissolved solids, seawater or highly saline water has resistivity down to $0.2 \Omega \mathrm{m}$ (Palacky 1987), which makes resistivity method the most ideal technique to distinguish the interface between saline and fresh water.

The study area is situated at latitude $\mathrm{N} 3^{0} 15^{\prime}$ and longitude E6 ${ }^{0} 29$ '. Physiographically, it lies within the limestone geomorphic units of the Ogun State, near Ewekoro formation. Major access road that link Lagos and Abeokuta pass through the study area. The study area falls within the sedimentary basin of Dahomy and the geology is made of sediment from Abeokuta, Ilaro, Ewekoro and Ibese formations. The oldest formation in Dahomy basin is Abeokuta formation. The area falls under the sedimentary Complex area of Ogun State, Southwestern Nigeria. The sedimentary rocks comprise of marls, silt, dolomite, limestone, anthracites, clay and shale. The occurrence of groundwater in crystalline rocks depends on the extent and depth of weathering and fractures (Witherly K.E. and Vyselaar, J, 1990). Basement aquifers are developed within either the regolith (relatively high storativity but low permeability) or the fractured bedrock (low storage capacity with a relatively high permeability). The groundwater is contained in the weathered/fractured formations and is primarily recharged through surface precipitation and secondarily through lateral flow from tributaries (Oseji J. O, 2010).

\section{MATERIALS AND METHOD:}

The study area is situated at co-ordinateE006.842660 and N03.194811 of Arigbajo, Ewekoro local government in Ogun State, Nigeria.

The formation consists of sandstone, oil sand. Alluvia, marls, shale, silt stone dolomite, mudstone, and limestone with Arigbajo Sandstone outcropping in some places as a distinct member. The high permeability of the soil cover and the underlying Sands in the western upland area facilitate groundwater recharge (Okoro I, E, 2010). The method adopted in this study was the engagement of the 2 - D electrical resistivity survey methods, using the ABEM SAS 4000 (terrameter) in the geophysical measurement.

The fundamental physical law used in resistivity surveys is Ohm's Law that governs the flow of current in

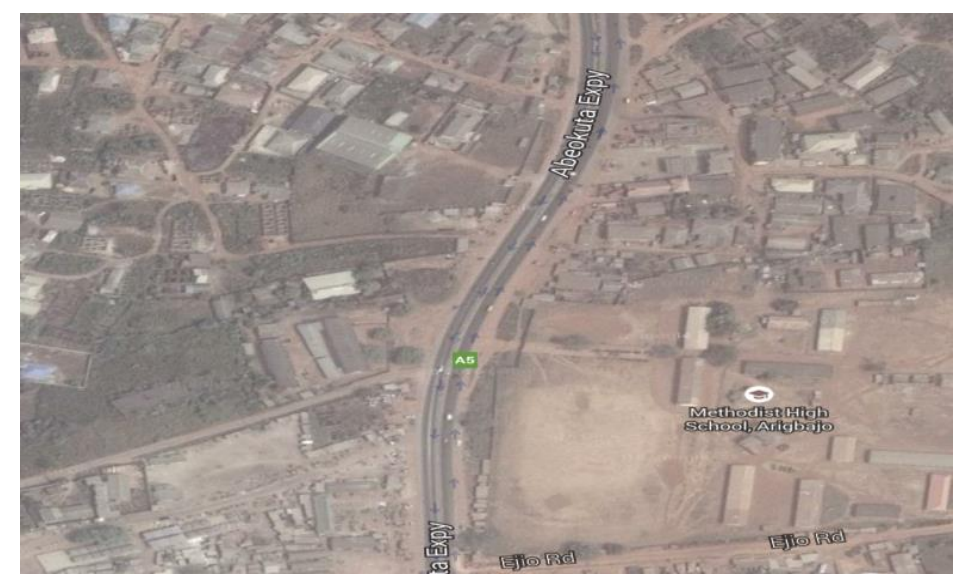

Fig 2a. Satellite mag of Arigbajo 


\section{International Journal of Engineering Applied Sciences and Technology, 2020 \\ Vol. 5, Issue 5, ISSN No. 2455-2143, Pages 60-66 \\ Published Online September 2020 in IJEAST (http://www.ijeast.com)}

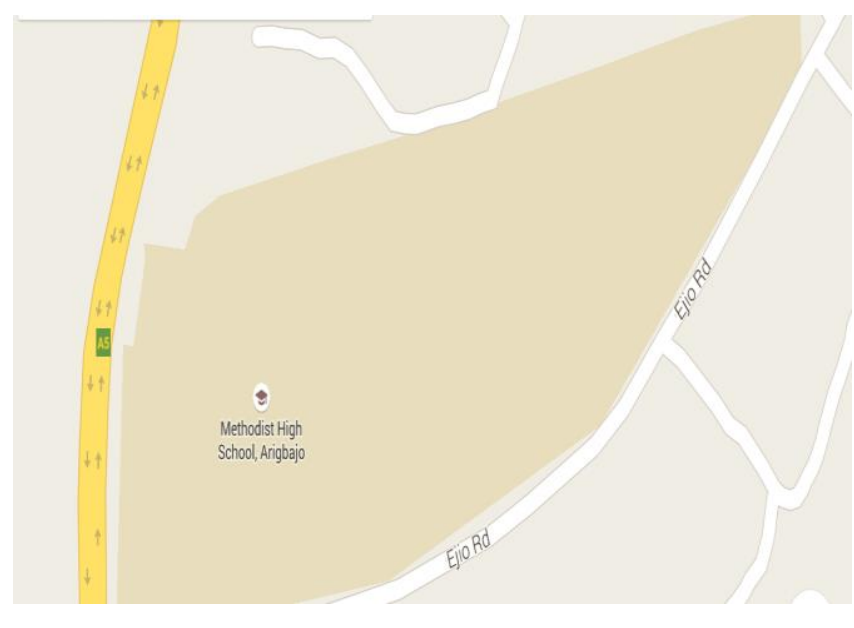

Fig 2b.Terrain map of Arigbajo.

the ground. The equation for Ohm's Law in vector form for current flow in a continuous medium is given by

$$
\mathrm{J}=\sigma \mathrm{E}
$$

Where $\sigma$ is the conductivity of the medium, $\mathrm{J}$ is the current density and $E$ is the electric field potential. In geophysical surveys the medium resistivity $\rho$, which is equals to the reciprocal of the conductivity $(\rho=1 / \sigma)$, is used. The relationship between the electric potential and the field intensity is given by

$$
\mathrm{E}=-\nabla \Phi
$$

Combining equations (1.1) and (1.2), we get

$$
\mathrm{J}=-\sigma \nabla \Phi
$$

In almost all surveys, the current sources are in the form of point sources. In this case, over an elemental volume $\Delta \mathrm{V}$ surrounding the current, I, source located at $\left(\mathrm{x}_{\mathrm{s}}, \mathrm{y}_{\mathrm{s}}, \mathrm{z}_{\mathrm{s}}\right)$ the relationship between the current density and the current (Dey and Morrison 1979a) is given by

$\nabla \mathrm{J}=(\mathrm{I} / \Delta \mathrm{V}) \delta\left(\mathrm{x}-\mathrm{x}_{\mathrm{s}}\right) \delta\left(\mathrm{y}-\mathrm{y}_{\mathrm{s}}\right) \delta\left(\mathrm{z}-\mathrm{z}_{\mathrm{s}}\right)$,

where $\delta$ is the Dirac delta function. Equation (3) can then be rewritten as

$$
\left.\underset{\left.\mathrm{y}_{\mathrm{s}}\right) \delta\left(\mathrm{z}-\mathrm{z}_{\mathrm{s}}\right)}{-\nabla \cdot[\sigma(\mathrm{x}, \mathrm{y}, \mathrm{z})} \nabla \Phi(\mathrm{x}, \mathrm{y}, \mathrm{z})\right]=(\mathrm{I} / \Delta \mathrm{V}) \delta\left(\mathrm{x}-\mathrm{x}_{\mathrm{s}}\right) \delta(\mathrm{y}-
$$

This is the basic equation that gives the potential distribution in the ground due to a point current source. A large number of techniques have been developed to solve this equation. This is the "forward" modeling problem, i.e. to determine the potential that would be observed over a given subsurface structure. Fully analytical methods have been used for simple cases, such as a sphere in a homogenous medium or a vertical fault between two areas each with a constant resistivity. For an arbitrary resistivity distribution, numerical techniques are more commonly used. For the 1-D case, where the subsurface is restricted to a number of horizontal layers, the linear filter method is commonly used (Koefoed 1979). For 2-D and 3-D cases, the finite-difference and finite-element methods are the most versatile. The equipotential surfaces have a hemisphere shape, and the current flow is perpendicular to the equipotential surface. The potential in this case is given by

$$
\phi=\rho 1 / 2 \pi \mathrm{r}
$$

where $r$ is the distance of a point in the medium (including the ground surface) from the electrode. Resistivity surveys use at least two current electrodes, one is the positive current ,I, sourceand the other is the negative currentsource. The potential values have a symmetrical pattern about the vertical place at the mid-point between the two electrodes. The potential value in the medium from such a pair is given by

$$
\phi=\rho 1 / 2 \pi\left(1 / \mathrm{r}_{\mathrm{c} 1}-1 / \mathrm{r}_{\mathrm{c} 2}\right)
$$

where $r_{C 1}$ and $r_{C 2}$ are distances of the point from the first and second current electrodes. In all surveys, the potential difference between two points (normally on the ground surface) is measured. In the 4 electrodes arrangement the potential difference is then given by

$\phi=\rho \mathrm{l} / 2 \pi\left(1 / \mathrm{r}_{\mathrm{c} 1 \mathrm{p} 1}-1 / \mathrm{r}_{\mathrm{c} 2 \mathrm{p} 1}-1 / \mathrm{r}_{\mathrm{cl} \mathrm{p} 2}+1 / \mathrm{r}_{\mathrm{c} 2 \mathrm{p} 2}\right)$

The above equation gives the potential that would be measured over a homogenous half space with a 4 electrodes array. The resistivity measurements are made by injecting current into the ground through the two current electrodes (C1 and $\mathrm{C} 2$ ), and measuring the resulting voltage difference at two potential electrodes (P1 and P2). From the current (I) and potential $(\Delta \varphi)$ values, an apparent resistivity $\left(\mathrm{p}_{\mathrm{a}}\right)$ value is calculated.

$$
\rho_{\mathrm{a}}=\mathrm{k} \Delta \varphi / 1
$$

where

$$
\mathrm{k}=2 \pi /\left[\left(1 / \mathrm{r}_{\mathrm{clp} 1}-1 / \mathrm{r}_{\mathrm{c} 2 \mathrm{p} 1}-1 / \mathrm{r}_{\mathrm{cl} p 2}+1 / \mathrm{r}_{\mathrm{c} 2 \mathrm{p} 2}\right)\right],
$$

$\mathrm{k}$ is a geometric factor that depends on the arrangement of the four electrodes. Resistivity measuring instruments normally give a resistance value, $\mathrm{R}=\Delta \varphi / \mathrm{I}$, so that the apparent resistivity value is calculated by

$$
\rho_{\mathrm{a}}=\mathrm{k} \mathrm{R}
$$

The calculated resistivity value is not the true resistivity of the subsurface, but an "apparent" value that is the resistivity of a homogeneous ground that produce the same resistance value for the same electrode arrangement. The relationship between the "apparent" resistivity and the "true" resistivity is a complex relationship. To determine the true subsurface 
resistivity from the apparent resistivity values is the "inversion" problem.

\section{RESULTS AND DISCUSSION}

The geophysics research analysis had been done at Arigbajo, Ewekoro Local government in Ogun State. The total of five traverse of $1.26 \mathrm{~km}$ had been analyzed in this area and the data collected from the 2D LUND Imaging Resistivity profiles are shown in the figures below.

\section{Station 1}

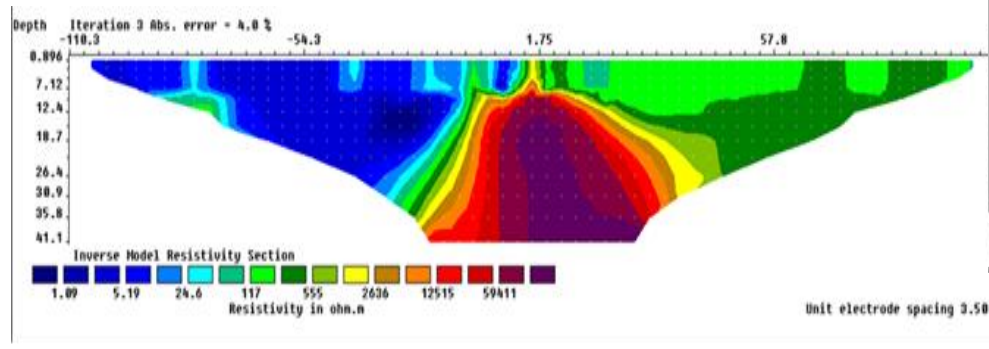

Traverse inversive section of station 1

Station 2

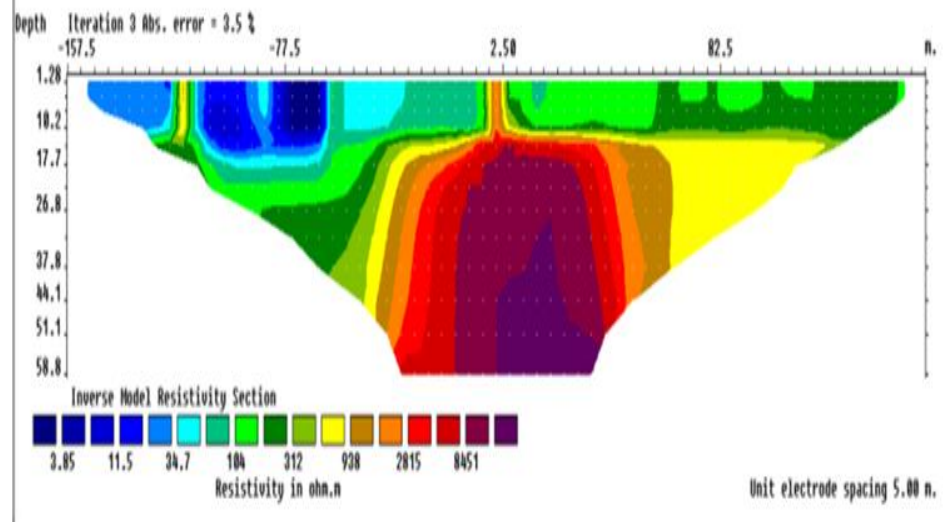

Traverse inversive section at station 2

\section{Station 3}

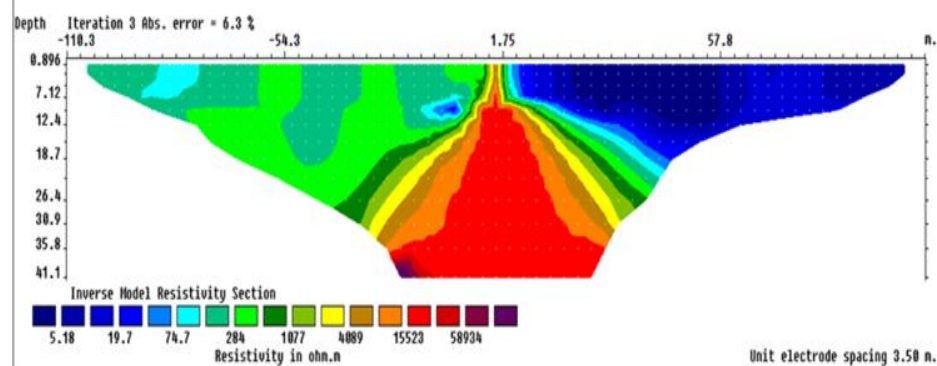

Station 4

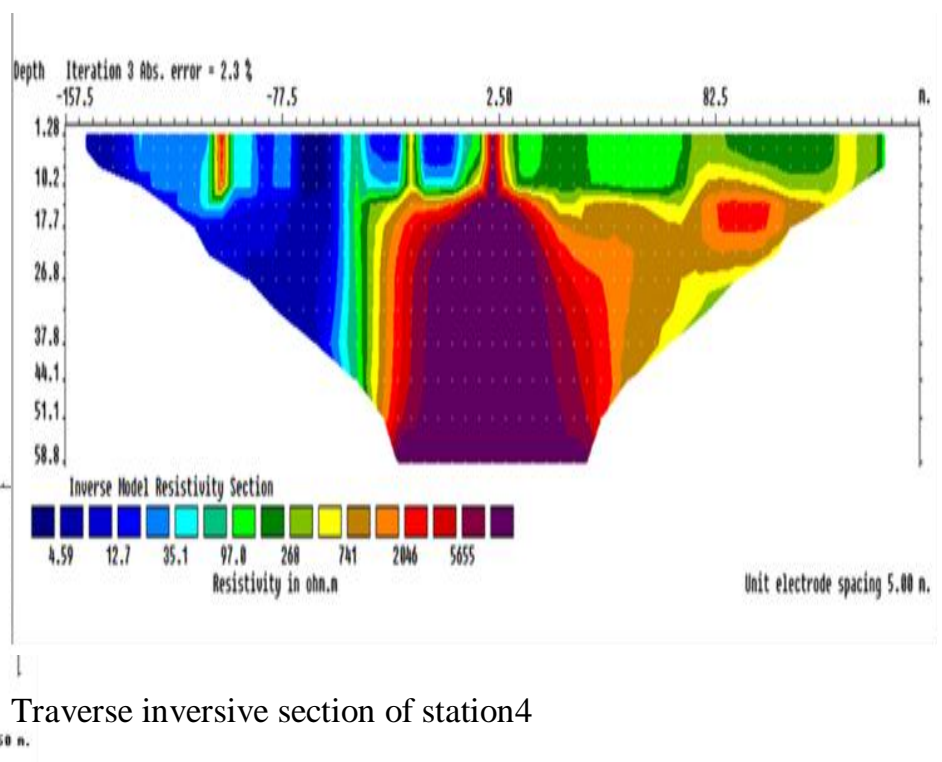

Station 5

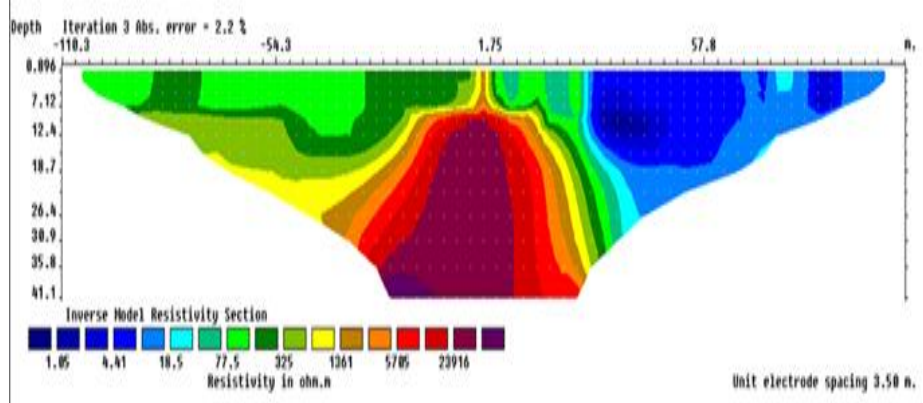

Traverse inversive section of station 5

\subsubsection{STATION 1}

In station 1 the line measure resistivity is situated at N6.3324, E003.5113 with length $220.6 \mathrm{~m}$. At $30 \mathrm{~m}$ into the lithosphere, the resistivity value ranges from 5 to $10 \Omega \mathrm{m}$. This is observed within -110 and -15 of the horizontal coordinate indicating the presence of oil sand and sandy-clay. Also, at $30 \mathrm{~m}$ deep the resistivity value was observed to be between 10 to $150 \Omega \mathrm{m}$. This indicates the presence ofalluvia, silt, and sandstone are present. This shows that the area has groundwater reservoir and therefore recommended to make a borehole. Also at $40 \mathrm{~m}$ deep high resistivities between 500 and $2000 \Omega \mathrm{m}$ was observed. Shale, dolomite and limestone are suspected to be present. Higher resistivities within 12,000 and $50,000 \Omega \mathrm{m}$ was recorded at $41 \mathrm{~m}$. This shows the presence of, shale and quartzite, marble granite, gabbro and hornfel in large quantity.

Traverse inversive section of station 3 


\section{International Journal of Engineering Applied Sciences and Technology, 2020 \\ Vol. 5, Issue 5, ISSN No. 2455-2143, Pages 60-66 \\ Published Online September 2020 in IJEAST (http://www.ijeast.com)}

\subsubsection{STATION 2}

In station 2 the line measure resistivity is situated ayN006.842660, E03.194811 with length 315m.At shallow depth of about $12 \mathrm{~m}$, the resistivity values ranging between $3 \Omega \mathrm{m}$ and $13 \Omega \mathrm{m}$ shows the presence of oil sand, sandy-clay. Also, the resistivity values between 10 and $100 \Omega \mathrm{m}$ at $17 \mathrm{~m}$ to about $30 \mathrm{~m}$ deep shows the presence of alluvia, silt, schist, aquifer and sandstone. This shows that the area hasgroundwater reservoir and therefore recommended to make a borehole. Higher resistivities at the middle of the horizontal line within depth 18 to $58 \mathrm{~m}$ having resistivity as high as 2,000 to $10,000 \Omega \mathrm{m}$ indicate the presence of dolomite, limestone, shale and sandstone in large quantity.

\subsubsection{STATION 3}

In station 3 the line measure resistivity is situated at the coordinate on N006.842666 and E03.194821 with length $220.6 \mathrm{~m}$. At shallow depth of about $12 \mathrm{~m}$, the values of the resistivity ranges between 5 to $12 \Omega \mathrm{m}$. Shows the presence of alluvia, oil sand, and sandy-clay. Directly under it at dept up to $26 \mathrm{~m}$ where the resistivity is between 19 to $80 \Omega \mathrm{m}$ show alluvia, silt, schist and sandy-clay. the same also appear from point 60 to 90 of the horizontal line. This shows that the area has groundwater reservoir and therefore recommended to make a borehole. High resistivity of about 12,000 to $50,000 \Omega \mathrm{m}$ was also recorded at shallow Dept of $12 \mathrm{~m}$ and deep depth of $41 \mathrm{~m}$. These indicate the presence of dolomite, limestone, shale and sandstone in large quantity.

\subsubsection{STATION 4}

In station 4 the line measure resistivity is situated at N006.8426651, E03.194851 with length 315m. At the depth of about $40 \mathrm{~m}$, the resistivity values ranging between $0 \Omega \mathrm{m}$ and $20 \Omega \mathrm{m}$ shows the presence of clay, oil sand and alluvia. Groundwater was suspected when the resistivity value was between $50 \Omega \mathrm{m}$ and $100 \Omega \mathrm{m}$ but at a low quantity. Meanwhile, the center of the horizontal line show higher resistivity of 1000 to $6000 \Omega \mathrm{m}$ which is an evidence of having large deposit of limestone, shale and sandstone.

\subsubsection{STATION 5}

In station 5 the line measure resistivity is situated at the coordinate N006.842621, E03.194842 with length $220.6 \mathrm{~m}$. Limestone, dolomite, sandstone and shale are present at deeper depth above $40 \mathrm{~m}$ but between 5 to $12 \mathrm{~m}$, groundwater exists. Also alluvia, oil sand, marl and sandstone is present between 15 and $30 \mathrm{~m}$ into the earth crust. On the right hand side of the horizontal axis the resistivity is low within the range of 0 to $15 \Omega \mathrm{m}$ as deep as about $26 \mathrm{~m}$. This indicates that oil sand, clay and marls are present.

\section{CONCLUSION}

Groundwater usually occurs in discontinuous aquifers in basement of complex areas. Stations 1, 2 and 3 show remarkable quantity of groundwater because of the intricate properties of the basement rocks while stations 4 and 5 show aquitard properties and cannot be recommended for drilling borehole. Meanwhile large deposit of limestone and dolomite was confirmed in all researched stations.2 - D resistivity have shown to be efficient in classifying lithospheric sequence and identifying groundwater potential at different basement terrain. Geophysical survey should be encouraged to identify areas of high groundwater potential in other to ensure proper position for drilling borehole that will supply water for a reasonably long period of time.

\section{ACKNOWLEDGEMENT}

I would like to express my special thanks of gratitude to The Bells University of Technology, Ota, Nigeria, University of Lagos, University of Calabar and Adeleke University, Ede as well as our Head of Departments for giving us a research enabling environment.

Secondly I would also like to thank Arigbajo Community leader who allowed us to carry out research within their domain despite the unfavourable condition.

\section{REFERENCES}

[1] A. A. Bordalo, W. Nilsumranchit and K. Chalermwat,(2001). "Water Quality and Uses of the Bangpakong River,'Wa- ter Research, Vol. 35(15), (pp. 3635-3642).

[2] A. E. Gobo, “Meteorology and Man's Environment,"African-link Books, Ibadan, 1998.

[3] Akinmosin A. Odewande, A. A. and Akintola A. I., (2005). "Geochemical Composition and Textural Features of Some Carbonate Rocks in Parts of Southwestern Nigeria". Ife Journal of Science 7, (1): (pp. 101-111).

[4] Akinyemi O.D, Adesegun B. and Akinpelu S., (2012) "Permeability of Abeokuta Riverbed Sediments". Special Topics \& Reviews in Porous Media - An International Journal, 3 (3): (pp. 289-296).

[5] Andras B, W. E. Kelly and Istva B., (1986). "Network design of geoelectric surveys for estimating aquifer properties. Integrated Design of Hydrological Networks" (Proceedings of the Budapest Symposium, July1986).IAHS Publ.no.158.

[6] Burger H. R., Exploration Geophysics of the Shallow Subsurface (Prentice -Hall, Englewood Cliffs, NJ, 1992)

[7] Ehirin C. N. and Ebeniro J. O. (2010) "Evaluation of Aquifer Characteristic and Groundwater Potential in Awka, 


\section{International Journal of Engineering Applied Sciences and Technology, 2020 \\ Vol. 5, Issue 5, ISSN No. 2455-2143, Pages 60-66 \\ Published Online September 2020 in IJEAST (http://www.ijeast.com)}

southeast Nigeria, Using Vertical Electrical Sounding”. Asian Journal of Earth Science, 2010

[8] Heigold, P.C., Gikeson, R.H., Cartwright K. and Reed P.C. (1979) "Aquifer Transmissivity from surficial electrical methods". Ground Water 17(4), July-August, (pp. 330-345).

[9] Huntley, D., 1986.Relations between permeability and electrical resistivity in granular aquifers. Gwater J. 24 (4)(pp. 466-474).

[10] K. A. B. Okoko and J. N. Nna, "Emerging Trends and Community Perception in the Nigerian Oil Industry," Nigerian Journal of Oil and Politics, Vol. 1, No. 2, 1998, (pp. 44-54).

[11] Kelly, W.E., (1977). Geoelectrical sounding for estimating aquifer hydraulic conductivity.G.water J. vol 50 (6): pp 420-425

[12] Loke M. H., (1994) "The inversion of two-dimensional resistivity data". Unpubl. PhD thesis, Un. Of Birmingham.

[13] Loke M. H., (1999) "Time-lapse resistivity imaging inversion". Proceedings of the 5th Meeting of the Environmental and Engineering Geophysical Society European Section, Em1.

[14] Loke M. H., (2000) "Topographic modeling in resistivity imaging inversion". 62nd EAGE Conference \& Technical Exhibition Extended Abstracts, D-2.

[15] L. Y. Khuan, N. Hamzah and R. Jailani, "Prediction of Water Quality Index (WQI) Based on Artificial Neutral Network," Student Conference on Research and Development Proceedings, Shah Alam, 2002.

[16] Mazac, O., Cislerova, M. and Vogel, T. (1988). Application of geophysical methods in describing spatial variability of saturated hydraulic conductivity in the zone of aeration. J. of Hydrology 103: (pp.117-126).

[17] McAlister J. B, Sternberg E.O, Wieduwilt B. K and Ward S. H., (Eds), (1990) "Induced polarization: Applications and case histories": Investigations in Geophysics No. 4, Soc. Expl.Geophys.

[18] M. D. Darefaka, "Water Quality Standards and Guidelines in Nigeria,( 2003). 2nd Earthwatch Conference on Water, Port Harcourt, (pp.16 - 18).

[19] Mendosa, F.G., Steenhuis, S.T., Todd, W.M., and Parlange, J.Y. 2003. "Estimating basin wide hydraulic parameters of a semi-arid mountainous water shed by recession-flow analysis". J. of hydrology (pp. 57-69).

[20] Odoh B. I., Utom A. U., Nwaze S. O., (2012). "Groundwater Prospecting in Fractured Shale Aquifer Using an Integrated Suite of Geophysical Methods: a Case History from Presbyterian Church, Kpiri-Kpiri, Ebonyi State, SE Nigeria”. Geosciences 2012, vol 2(4): (pp. 60-65).

[21] Okolie E. C, Osemeikhian J. E. A, Oseji J. O, Atakpo E., (2005)“Geophysical Investigation of the source of River Ethiope" in UkwuaniLocal Government area of Delta State. Niger. Inst. Phys.

Vol (17):(pp. 21-26).

[22] Okoro E. I. Egboka B. C. E. Onwuemesi A. G., (2010) "Evaluation of the aquifer characteristic of Nanka Sands using hydrogeological method in combination with Vertical Electrical Sounding (VES)" J. Appl. Sci. Environ. Manage. June, 2010 Vol. 14 (2) (pp. 5 - 9)

[23] Onuoha, K.M. and Mbazi F.C.C., (1988) "Aquifer Transmissivity from Electrical Sounding Data of the Case of Ajali Sandstone Aquifers, South East of Enugu, Nig.". In: C.O. Ofoegbu (ed.). Groundwater and Mineral Resources of Nig. Fried-vieweg\& Son Pub.: Berlin, Germany. (pp.17-29).

[24] Opara A. I. Onu N.N., and Okereafor D.U., "Geophysical Sounding for the Determination of Aquifer Hydraulic Characteristics from Dar- Zurrock Parameters: Case Study of NgorOkpala, Imo River Basin in Southeastern Nigeria". Department of Geosciences, Federal University of Technology, Owerri, Nigeria.

[25] Oseji J. O., (2010) Geoelectric investigation of groundwater resources and aquifer characteristics in UtagbaOgbe kingdom Ndokwa land area of Delta State, Nigeria. Journal of Environmental Chemistry and Ecotoxicology Vol. 2(3), (pp. 38-46).

[26] Rhett H., (2001)“an introduction to electrical resistivity in geophysics". Department of Chemistry and Physics and Department of Geology, Radford University, Radford, Virginia.

[27] Sandberg S. K. Slater L. D. Versteeg R., (2002) “An integrated geophysical investigation of the hydrogeology of an anisotropic unconfined aquifer". Journal of Hydrology 267 (pp.227-243)

[28] Selvam S. Sivasubramanian P., (2012). "Groundwater potential zone identification using geoelectrical survey: A case study from Medak district, Andhra Pradesh, India”. International journal of geomatics and geosciences Volume 3(1), 2012.

[29] Tong L. and Yang C., (1990) "Incorporation of topography into two-dimensional resistivity inversion". Geophysics, vol 5(5), (pp. 354-361).

[30] Uma K.O., (1989) "An Appraisal of the Groundwater Resources of the Imo River Basin".Nigerian Journal Mining Geology.Vol 19(25): (pp305-315). 
[31] Witherly, K.E. and Vyselaar, J, (1990) "A geophysical case history of the Poplar Lake Copper-Molybdenum deposit, Houston Area, British Columbia. in Fink"

[32] Zonge K. L, and Wynn J. C., (1975) "Recent advances and applications in complex resistivity Measurements". Geophysics, vol 40: (pp. 851-864). 